\title{
Effects of milk supplementation with conjugated linoleic acid (isomers cis-9, trans-11 and trans-10, cis-12) on body composition and metabolic syndrome components
}

\author{
Nuria Laso ${ }^{1}$, Emma Brugué ${ }^{2}$, Josep Vidal ${ }^{2}$, Emilio Ros $^{2}$, Joan Albert Arnaiz ${ }^{3}$, Xavier Carné ${ }^{3}$, Sergi Vidal ${ }^{4}$, \\ Sergi Mas ${ }^{1}$, Ramon Deulofeu ${ }^{5}$ and Amalia Lafuente ${ }^{1 *}$ \\ ${ }^{1}$ Dep. Farmacología y Química Terapéutica, Universidad de Barcelona, IDIBAPS, Casanova 143, E-08036 Barcelona, Spain \\ ${ }^{2}$ Endocrinology Service, Hospital Clínico Universitario de Barcelona, Villarroel 170, 08036 Barcelona, Spain \\ ${ }^{3}$ Clinical Pharmacology Service, Hospital Clínico Universitario de Barcelona, Villarroel 170, 08036 Barcelona, Spain \\ ${ }^{4}$ Nuclear Medicine Service, Hospital Clínico Universitario de Barcelona, Villarroel 170, 08036 Barcelona, Spain \\ ${ }^{5}$ Clinical Biochemistry Service, Hospital Clínico Universitario de Barcelona, Villarroel 170, 08036 Barcelona, Spain
}

(Received 20 December 2006 - Revised 12 March 2007 - Accepted 27 March 2007)

\begin{abstract}
The effects of conjugated linoleic acid (CLA) on body weight and body composition in man are controversial. The aim of this study was to investigate the effects of milk supplementation with CLA on body composition and on the biochemical parameters of the metabolic syndrome. This was a randomised, double-blind, placebo-controlled trial. Subjects were randomised to a daily intake of $500 \mathrm{ml}$ milk supplemented with $3 \mathrm{~g}$ CLA (using a mixture of the bioactive isomers cis-9, trans-11 and trans-10, $c i s-12$, marketed as Tonalin ${ }^{\circledR}$, Naturlinea; Central Lechera Asturiana) or placebo for 12 weeks. Sixty healthy men and women (aged 35-65 years) with signs of the metabolic syndrome participated (BMI $\left.25-35 \mathrm{~kg} / \mathrm{m}^{2}\right)$. Dualenergy X-ray absorptiometry was used to measure body composition (week 0 baseline and week 12). Total fat mass in the CLA-milk subgroup with a BMI $\leq 30 \mathrm{~kg} / \mathrm{m}^{2}$ decreased significantly while no changes were detected in the placebo group $(\sim 2 \%, P=0 \cdot 01)$. Trunk fat mass showed a trend towards reduction $(\sim 3 \%, P=0.05)$. CLA supplementation had no significant effect on the parameters of the metabolic syndrome, nor was it associated with changes in haematological parameters or renal function. The supplementation of milk with $3 \mathrm{~g}$ CLA over 12 weeks results in a significant reduction of fat mass in overweight but not in obese subjects. CLA supplementation was not associated with any adverse effects or biological changes.
\end{abstract}

Conjugated linoleic acid: Body fat composition: Metabolic syndrome: Man: BMI

Conjugated linoleic acid (CLA) is a mixture of linoleic acid isomers with conjugated double bonds. This fatty acid is produced naturally in the rumen of ruminant animals by biohydrogenation of linoleic acid or synthetically ${ }^{1}$. CLA was first identified when extracts from fried beef were found to be anticarcinogenic ${ }^{2}$. This effect was confirmed in animal and in vitro models of carcinogenesis ${ }^{3-8}$. Further studies showed other beneficial effects of this CLA, including protection against arteriosclerosis, immune stimulation and modulation of body composition ${ }^{9-12}$.

The main isomer of CLA in natural foods is cis-9, trans-11, but trans-10, cis-12 is the isomer that affects energy metabolism and body fat deposition and composition in mice ${ }^{11,12}$. The main dietary source of CLA for man is ruminant meats, such as beef and lamb, and dairy products, such as milk and cheese. The mean estimated daily CLA intake is $0 \cdot 3-2.6 \mathrm{~g} / \mathrm{d}^{13,14}$, but in recent years, dietary changes have resulted in a decrease of CLA consumption.
It has been proposed that supplementing food with CLA could benefit health ${ }^{15}$. The effects of CLA on body weight and body composition in man are documented, although some clinical studies in this field have been short term or have included a small sample of subjects ${ }^{16}$. Moreover, the type of CLA isomer and the dose used varied between studies which may account for the discordant results. While some studies using a mixture of the bioactive isomers cis-9, trans-11 and trans-10, cis-12, reported reductions in body fat mass (BFM) ${ }^{17-20}$ or an increase in lean body mass ${ }^{17,18,21}$, other short-term studies showed no effect on body composition ${ }^{22-25}$.

Here we examined the effect of a $50 \%$ mixture of the two active CLA isomers (cis-9, trans-11 and trans-10, cis-12; Tonalin ${ }^{\circledR}$, Naturlinea; Central Lechera Asturiana, Spain) added to a skimmed milk, on BFM, lean body mass, BMI and biochemical parameters related to the metabolic syndrome. Although no serious toxic effects of CLA have been reported, we also evaluated alterations in the hepatic 
and renal function in addition to changes in haematological parameters.

\section{Methods}

We performed a randomised, double-blind, placebo-controlled dietary intervention trial. Participants in the study were men and women ( $n$ 60), aged 35-65 years, with a BMI of 25-35 $\left(\mathrm{kg} / \mathrm{m}^{2}\right)$ and with a waist diameter $>102 \mathrm{~cm}$ in men and $>88 \mathrm{~cm}$ in women. Moreover, to be included in the study, subjects had to fulfil two additional National Cholesterol Education Program criteria for the metabolic syndrome, namely (1) systolic pressure $>130 \mathrm{mmHg}$ or diastolic blood pressure $>85 \mathrm{mmHg}$; (2) fasting plasma glucose $>110 \mathrm{mg} / \mathrm{dl}$; (3) HDL-cholesterol $<50 \mathrm{mg} / \mathrm{dl}$ in women and $<40 \mathrm{mg} / \mathrm{dl}$ in men; (4) TAG $>150 \mathrm{mg} / \mathrm{dl}$. Otherwise participants were apparently healthy. Finally, participants had to show a stable weight defined as a body weight variation of $<5 \%$ in the 3 months previous to the study. Exclusion criteria included: alcoholism, active thyroid disease, diabetes mellitus treated with insulin or drugs, renal or liver dysfunction, and malignant tumours or other serious diseases. Moreover, subjects on antiobesity drugs, with dietary variations of over $10 \%$ in $\mathrm{kJ} / \mathrm{d}$ during the study, subjects taking adrenergic agonists $(\alpha, \beta$ or both), pregnant or lactating women and subjects participating in another dietetic study were also excluded. The study was approved by the Ethical Research Board of the Hospital Clinic. Patients gave their signed informed consent. All subjects were recruited either from a primary care centre or an outpatient clinic dealing with cardiovascular risk. Subjects were randomised to receive $3 \mathrm{~g}$ CLA (using a mixture of the bioactive isomers cis-9, trans-11 and trans-10, cis-12; Tona$\operatorname{lin}^{\circledR} ; n$ 30) in $500 \mathrm{ml}$ skimmed milk $(0.3 \%$ total fat mass; Central Lechera Asturiana) or placebo $(500 \mathrm{ml}$ of the same skimmed milk; $n$ 30) every day for 12 weeks. Packages of milk were delivered monthly by a home delivery service. The study protocol is summarised in Fig. 1. In brief, demographic data were recorded when subjects began the study (at week -6). Weight, waist circumference, BMI, blood pressure, dietary control and adverse effects were recorded on each monthly visit (week -6 , week 0 , week 4 , week 8 , week 12). Body composition was analysed by dual-energy X-ray absorptiometry (DEXA; with a Lunar Prodigy and software version 5.6). BFM (trunk and total) and lean body mass (trunk and total) were assessed at each time-point.

Blood samples were obtained from fasting subjects in week -6 to check whether they met the inclusion criteria and again at week 0 and week 12 . All samples were analysed in the same laboratory. The following analytic variables were studied:

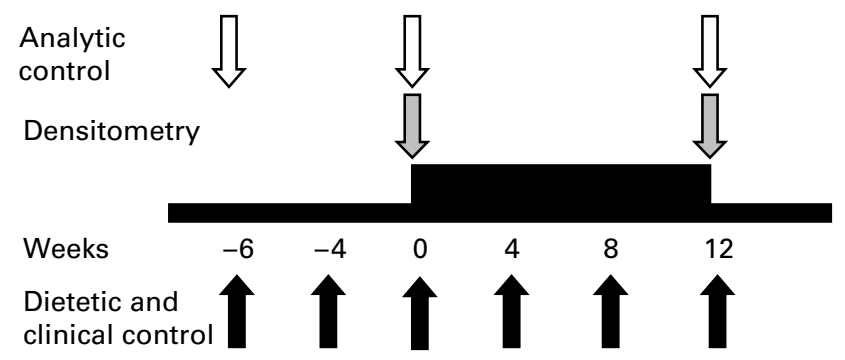

Fig. 1. Study design. metabolic syndrome parameters (HDL-cholesterol, TAG, fasting plasma glucose and fasting immunoreactive insulin) and security parameters (haematological profile, renal and hepatic function). Insulin sensitivity was estimated from the HOMAIR index [HOMA-IR $=$ fasting glucose $(\mathrm{mmol} / \mathrm{l}) \times$ fasting immunoreactive insulin $(\mu \mathrm{U} / \mathrm{ml}) / 22 \cdot 5]$.

Compliance and changes in the current diet were assessed through $3 \mathrm{~d}$ diet records on each visit. Each subject also completed a FFQ at weeks $-6,0$ and 12 . A dietitian provided general counselling at the beginning of the study with detailed instruction on how to complete the FFQ, but no specific limits were set regarding energy intake or dietary habits. A software program, Dietsource ${ }^{\circledR}$ (Novartis, Switzerland) was used to calculate energy intake and macro- and micronutrient distribution. The dietitian also gave recommendations about exercise which was monitored throughout the study using the International Physical Activity Questionnaire ${ }^{26}$. Three exercise categories were established (low, medium and intensive). Since the main aim of the study was to test the effects of CLA on body composition, subjects were excluded from the study when their total daily energy intake varied more than $10 \%$ or when the variation in energy intake had resulted in a weight change $>5 \%$ during the study.

Statistical analyses were performed using the SPSS software package version 11.0 (SPSS Inc., Chicago, IL, USA). Changes in anthropometric and analytical variables from baseline to week 12 in each study group were assessed by paired Student's $t$-test. An unpaired Student's $t$-test was used to compare the mean change in each study variable between the two treatment groups. ANOVA was used to test the overall effect of the CLA supplementation and the interaction between CLA and other parameters. At baseline, differences in qualitative variables (such as sex or tobacco consumption) were tested through $\chi^{2}$; Student's $t$-test was used to assess differences in continuous variables (age). $P<0.05$ was considered statistically significant.

\section{Results}

In our trial, ten participants from the CLA group and seven from the control group were excluded from analysis because of protocol violations: because of loss of follow-up (one participant from each group), dietary energy intake variations $\geq 10 \%$ during the study (seven participants from the CLA group and four participants from the placebo group), weight reduction $\geq 5 \%$ (one participant from the CLA group and two participants from the control group), both dietary and weight variations (one participant from the CLA group) (Fig. 2). There were no differences in exclusion percentages in the two groups ( $\chi^{2}$ NS). Primary DEXA and analysis were performed in the 'per protocol' population. Patients lost to follow-up and patients with major protocol violations (those with dietary or weight changes outside the pre-defined boundaries) were excluded from the study.

At baseline, mean age (CLA 54.79 (SE 7.55) years; placebo 52.92 (SE 7.92) years), sex (CLA $75 \%$ male; placebo $78 \%$ male) or tobacco consumption (CLA $31.5 \%$ smokers; placebo $41.6 \%$ smokers) showed no significant differences between the two groups. Alcohol consumption and exercise categories were also similar in the two groups. Likewise, at this timepoint, metabolic syndrome variables (Table 1) did not differ 


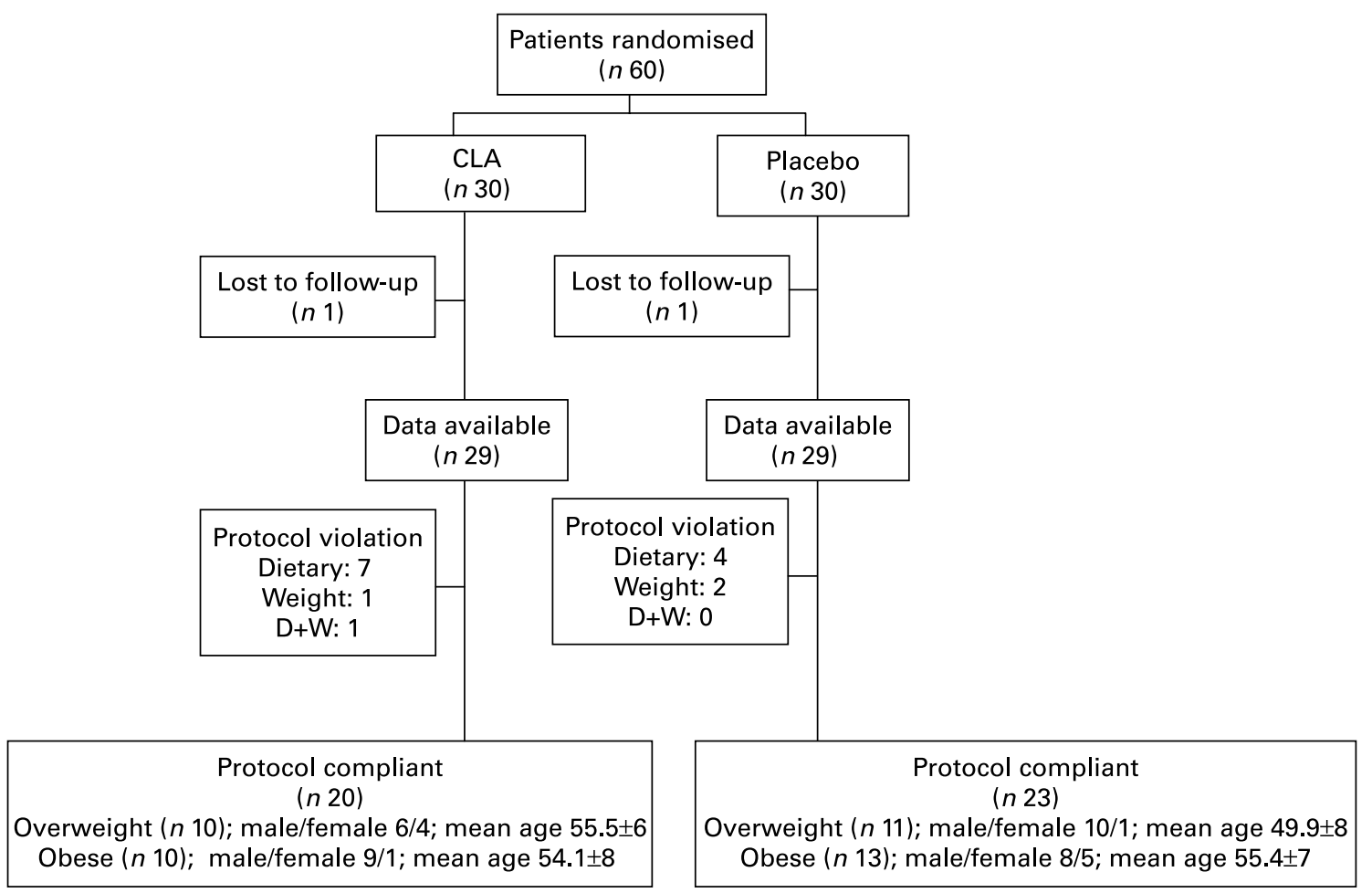

Fig. 2. Study participant data. CLA, conjugated linoleic acid.

Table 1. Clinical values of metabolic syndrome of subjects participating in the conjugated linoleic acid (CLA) and placebo groups, at week 0 (pre-value) and week 12 (post-value) and stratified by BMI at the beginning of the study

\begin{tabular}{|c|c|c|c|c|c|c|c|c|c|}
\hline & & \multicolumn{4}{|c|}{$\mathrm{BMI} \leq 30$} & \multicolumn{4}{|c|}{$\mathrm{BMI}>30$} \\
\hline & & \multicolumn{2}{|c|}{ CLA } & \multicolumn{2}{|c|}{ Placebo } & \multicolumn{2}{|c|}{ CLA } & \multicolumn{2}{|c|}{ Placebo } \\
\hline & & Mean & SE & Mean & SE & Mean & SE & Mean & SE \\
\hline \multirow[t]{2}{*}{$\mathrm{BMI}\left(\mathrm{kg} / \mathrm{m}^{2}\right)$} & Pre & $28 \cdot 1$ & 2 & $27 \cdot 1$ & 1 & $32 \cdot 8$ & 2 & $33 \cdot 4$ & 1 \\
\hline & Post & $27 \cdot 9$ & 2 & $27 \cdot 1$ & 1 & $32 \cdot 7$ & 2 & $33 \cdot 1$ & 2 \\
\hline \multirow[t]{2}{*}{ Systolic blood pressure $(\mathrm{mmHg})$} & Pre & $146 \cdot 1$ & 15 & $145 \cdot 0$ & 19 & $150 \cdot 5$ & 13 & $146 \cdot 9$ & 17 \\
\hline & Post & $142 \cdot 2$ & 20 & $148 \cdot 1$ & 25 & 155.5 & 12 & $150 \cdot 3$ & 18 \\
\hline \multirow[t]{2}{*}{ Diastolic blood pressure $(\mathrm{mmHg})$} & Pre & $83 \cdot 8$ & 9 & $81 \cdot 3$ & 8 & $87 \cdot 0$ & 10 & $85 \cdot 3$ & 11 \\
\hline & Post & $81 \cdot 6$ & 9 & $80 \cdot 9$ & 11 & 88.5 & 9 & $83 \cdot 8$ & 7 \\
\hline \multirow[t]{2}{*}{ Waist circumference $(\mathrm{cm})$} & Pre & 101.4 & 9 & 99.4 & 6 & 111.9 & 7 & 109.5 & 9 \\
\hline & Post & $101 \cdot 3$ & 9 & 99.0 & 6 & $111 \cdot 3$ & 8 & 109.4 & 10 \\
\hline \multicolumn{10}{|l|}{ Total intake } \\
\hline \multirow[t]{2}{*}{ in $\mathrm{kJ}$} & Pre & 9506.9 & 2456 & $10177 \cdot 6$ & 1879 & $9580 \cdot 9$ & 2079 & $8563 \cdot 8$ & 2289 \\
\hline & Post & 9614.8 & 2418 & 10391.0 & 2301 & 10139.9 & 1925 & $9207 \cdot 7$ & 1456 \\
\hline \multirow[t]{2}{*}{ in kcal } & Pre & $2272 \cdot 2$ & 587 & 2432.5 & 449 & $2289 \cdot 9$ & 497 & $2046 \cdot 8$ & 547 \\
\hline & Post & $2298 \cdot 1$ & 578 & 2483.5 & 550 & 2423.5 & 460 & $2200 \cdot 6$ & 348 \\
\hline \multirow[t]{2}{*}{ Glycaemia (mg/dl) } & Pre & $96 \cdot 4$ & 19 & $87 \cdot 2$ & 18 & 91.4 & 18 & $103 \cdot 4$ & 32 \\
\hline & Post & $90 \cdot 2$ & 11 & 83.7 & 20 & $87 \cdot 8$ & 23 & 102.9 & 41 \\
\hline \multirow[t]{2}{*}{ HDL-cholesterol (mg/dl) } & Pre & $47 \cdot 2$ & 8 & $39 \cdot 3$ & 7 & $46 \cdot 0$ & 11 & 43.2 & 7 \\
\hline & Post & $53 \cdot 2^{*}$ & 10 & $45 \cdot 1^{* *}$ & 6 & $49 \cdot 0$ & 11 & $45 \cdot 0$ & 9 \\
\hline \multirow[t]{2}{*}{ LDL-cholesterol (mg/dl) } & Pre & $159 \cdot 2$ & 37 & 134.0 & 37 & $153 \cdot 7$ & 29 & $161 \cdot 4$ & 38 \\
\hline & Post & $175 \cdot 6$ & 42 & $127 \cdot 0$ & 38 & $155 \cdot 8$ & 32 & $155 \cdot 1$ & 31 \\
\hline \multirow[t]{2}{*}{ Total cholesterol (mg/dl) } & Pre & $253 \cdot 3$ & 69 & $205 \cdot 5$ & 37 & $235 \cdot 2$ & 39 & 241.4 & 42 \\
\hline & Post & 262.5 & 61 & 204.9 & 43 & 244.4 & 41 & 234.6 & 38 \\
\hline \multirow[t]{2}{*}{ TAG (mg/dl) } & Pre & $170 \cdot 0$ & 107 & $161 \cdot 0$ & 88 & 183.9 & 141 & $183 \cdot 7$ & 51 \\
\hline & Post & $167 \cdot 6$ & 72 & 214.9 & 197 & $194 \cdot 3$ & 102 & 238.0 & 178 \\
\hline \multirow[t]{2}{*}{ HOMA-IR index§ } & Pre & $3 \cdot 2$ & 1 & $3 \cdot 0$ & 1 & $3 \cdot 7 \dagger$ & 3 & 6.6 & 3 \\
\hline & Post & $3 \cdot 1$ & 0 & $3 \cdot 2$ & 1 & 3.8 & 2 & $6 \cdot 7$ & 4 \\
\hline
\end{tabular}

Mean values were significantly different from the pre-values when comparing paired data within groups: ${ }^{*} P=0.02 ;{ }^{\star \star} P=0.009$.

Mean value was significantly different from that of the placebo group: $† P=0.04$.

$\S$ HOMA-IR $=$ fasting glucose $(\mathrm{mmol} / \mathrm{l}) \times$ fasting immunoreactive insulin $(\mu \mathrm{U} / \mathrm{ml}) / 22.5$. 
Table 2. Results of dual-energy X-ray absorptiometry, at week 0 (pre-value) and week 12 (post-value) and stratified by BMI at the beginning of the study

\begin{tabular}{|c|c|c|c|c|c|c|c|c|c|}
\hline & & \multicolumn{4}{|c|}{$\mathrm{BMI} \leq 30$} & \multicolumn{4}{|c|}{$\mathrm{BMI}>30$} \\
\hline & & \multicolumn{2}{|c|}{$\operatorname{CLA}(n 10)$} & \multicolumn{2}{|c|}{ Placebo $(n 11)$} & \multicolumn{2}{|c|}{$\operatorname{CLA}(n 10)$} & \multicolumn{2}{|c|}{ Placebo ( $n$ 13) } \\
\hline & & Mean & SE & Mean & SE & Mean & SE & Mean & SE \\
\hline \multirow[t]{3}{*}{ Trunk fat tissue $(\mathrm{kg})$} & Pre & $16 \cdot 7$ & 4 & $13 \cdot 7$ & 2 & $18 \cdot 7$ & 2 & 21.4 & 5 \\
\hline & Post & $16 \cdot 2$ & 4 & $13 \cdot 7$ & 2 & $19 \cdot 0$ & 2 & $21 \cdot 1$ & 5 \\
\hline & $\Delta$ & $-0.50 \ddagger$ & & 0.05 & & 0.26 & & -0.33 & \\
\hline \multirow[t]{3}{*}{ Total fat tissue $(\mathrm{kg})$} & Pre & $29 \cdot 1 \dagger$ & 7 & $22 \cdot 6$ & 3 & $32 \cdot 1$ & 5 & $36 \cdot 7$ & 7 \\
\hline & Post & $28 \cdot 5^{\star}$ & 6 & 22.9 & 4 & $32 \cdot 4$ & 5 & $36 \cdot 1$ & 8 \\
\hline & $\Delta$ & $-0.61 \neq \ddagger$ & & 0.28 & & 0.32 & & -0.67 & \\
\hline \multirow{3}{*}{ Trunk lean tissue $(\mathrm{kg})$} & Pre & 22.5 & 4 & $23 \cdot 8$ & 2 & $26 \cdot 9$ & 4 & $25 \cdot 6$ & 5 \\
\hline & Post & $22 \cdot 3$ & 4 & 23.5 & 2 & $27 \cdot 0$ & 4 & 25.9 & 5 \\
\hline & $\Delta$ & -0.15 & & -0.33 & & 0.08 & & 0.33 & \\
\hline \multirow[t]{3}{*}{ Total lean tissue $(\mathrm{kg})$} & Pre & 47.4 & 10 & $51 \cdot 3$ & 6 & $56 \cdot 1$ & 8 & $53 \cdot 2$ & 12 \\
\hline & Post & $47 \cdot 7$ & 10 & $51 \cdot 7$ & 6 & $56 \cdot 2$ & 8 & $53 \cdot 8$ & 13 \\
\hline & $\Delta$ & 0.32 & & 0.42 & & 0.06 & & 0.55 & \\
\hline
\end{tabular}

CLA, conjugated linoleic acid; $\Delta$, change.

Mean value was significantly different from the pre-value when comparing paired data within groups: ${ }^{*} P=0.02$.

Mean value was significantly different from those of the placebo group: $\dagger P=0.03$.

$\Delta$ Mean values were significantly different (CLA v. placebo): $\ddagger P=0.05 ; \ddagger \ddagger P=0.01$.

significantly between the two groups. In the overweight subgroup, total fat tissue was significantly higher in the CLA than in the placebo group at week 0 (Table 2).

Compliance with treatment was over $99 \%$. At week 12, daily energy intake, body weight and BMI had not altered from baseline values in either group.

When all subjects were considered, neither BFM (total fat tissue 30.6 to $30.5 \mathrm{~kg}$ in the CLA group; 30.3 to $30.0 \mathrm{~kg}$ in the placebo group) nor lean body mass $(52.0$ to $52.2 \mathrm{~kg}$ in the CLA group; 52.4 to $52.9 \mathrm{~kg}$ in the placebo group) differed significantly from baseline values. Gender did not affect these parameters. However, when subjects were stratified by BMI at week 0 (BMI $>30$ or $\leq 30 \mathrm{~kg} / \mathrm{m}^{2}$ ), we observed a slight but significant decrease in total fat mass and a trend towards a decrease in trunk fat mass in the CLA subgroup when comparing paired data within cases (pre $v$. post values), while no changes in the placebo group were detected (Table 2). The differences were statistically significant when the change $(\Delta)$ in BFM parameters were compared between the two groups, CLA $v$. placebo. When ANOVA was used to test the overall effect of the CLA supplementation $(F=0.02 ; P=0.8)$, BMI $(F=0.001 ; P=0.9)$ and interaction between the two, the former interaction was statistically significant $(F=8 \cdot 3$; $P=0.006$ ).

CLA supplementation was not associated with a significant change in any of the components of the metabolic syndrome compared with the control (Table 1). At week 12, there was no significant change in waist circumference, fasting plasma glucose, plasma TAG, total cholesterol, or systolic or diastolic blood pressure. LDL-cholesterol increased slightly in both CLA groups but these changes were not statistically significant. In contrast, in the subgroup of overweight patients, HDL increased in both groups. Insulin sensitivity at the end of the study period, as assessed from the HOMA-IR index, did not differ significantly from baseline levels. We did not observe a worsening in either hepatic or renal function markers, nor in haematological parameters in the CLA group
(Table 3). We detected a significant reduction of alanine aminotransferase, a marker of liver disease in the CLA overall group $(P=0 \cdot 01$; results not shown). The statistical significance disappeared when the groups were stratified by BMI. Eight subjects in the control group $(26.6 \%)$ and one case $(3.5 \%)$ in the CLA group presented mild intestinal adverse effects (laxative effects and flatulence).

\section{Discussion}

Milk supplementation with CLA ( $3 \mathrm{~g} / \mathrm{d})$ significantly reduces BFM after 12 weeks of treatment in overweight patients but not in grade I obesity subjects. Reductions affected both total and trunk values. We used DEXA technology to determine changes in body composition. This method has been validated by other studies and it can detect even small changes in body weight or composition.

The literature on the effects of CLA on body composition gives discordant results. Some of the factors that may account for disparity between studies are the type of CLA isomers used, the length of the treatment period and the type of patients enrolled. Table 4 shows some of the most relevant studies in this field. Most of the short-term assays (3 months) have been done with overweight patients. We believe that the lack of effect of CLA on BFM in obese subjects could be related to the short duration of the study. A 3- or 4-month study may not be long enough to detect all the changes caused by CLA. Only the study of Riserús et al. ${ }^{23}$ showed significant changes in obese subjects $(B M I \geq 30)$ after 3 months of treatment. However, anthropometric measurements may not be reliable. The study of Gaullier et al $^{27,28}$, the only long-term one (12 months and 24-month follow-up), was performed on overweight subjects (average BMI between 27 and 28). These subjects showed reductions of $7.5 \%$ in BFM from 6 to 12 months of treatment with CLA. If these changes in BFM are extrapolated to 3 months (Fig. 3), they would coincide with the $3 \%$ decrease observed in the present 
Table 3. Safety analysis, at week 0 (pre-value) and week 12 (post-value) and stratified by BMI at the beginning of the study

\begin{tabular}{|c|c|c|c|c|c|c|c|c|c|c|}
\hline & \multirow[b]{3}{*}{ Intervals reference } & & \multicolumn{4}{|c|}{$\mathrm{BMI} \leq 30$} & \multicolumn{4}{|c|}{$\mathrm{BMI}>30$} \\
\hline & & & \multicolumn{2}{|c|}{ CLA } & \multicolumn{2}{|c|}{ Placebo } & \multicolumn{2}{|c|}{ CLA } & \multicolumn{2}{|c|}{ Placebo } \\
\hline & & & Mean & SE & Mean & SE & Mean & SE & Mean & $\mathrm{SE}$ \\
\hline \multirow[t]{2}{*}{ Creatinine (mg/dl) } & $0.3-1.3$ & Pre & 1.0 & 0 & $1 \cdot 2$ & 0 & $1 \cdot 1$ & 0 & 1.2 & 0 \\
\hline & & Post & 1.0 & 0 & 1.2 & 0 & $1 \cdot 1$ & 0 & $1 \cdot 1$ & 0 \\
\hline \multirow[t]{2}{*}{ Insulin (mU/l) } & $12 \cdot 4 \pm 3$ & Pre & 13.6 & 4 & 13.9 & 3 & $15 \cdot 3$ & 10 & $25 \cdot 8$ & 7 \\
\hline & & Post & 13.9 & 3 & $15 \cdot 4$ & 6 & $17 \cdot 4$ & 9 & $25 \cdot 7$ & 13 \\
\hline \multirow{2}{*}{ AST (U/I) } & $5-40$ & Pre & 29.0 & 10 & $24 \cdot 6$ & 3 & $25 \cdot 0$ & 8 & $26 \cdot 6$ & 7 \\
\hline & & Post & $25 \cdot 0$ & 2 & $27 \cdot 0$ & 6 & 23.0 & 4 & $25 \cdot 9$ & 7 \\
\hline \multirow[t]{2}{*}{ ALAT (U/l) } & $5-40$ & Pre & 31.9 & 10 & 29.9 & 6 & 33.1 & 21 & $32 \cdot 8$ & 15 \\
\hline & & Post & $27 \cdot 3$ & 10 & 33.4 & 10 & $27 \cdot 2$ & 12 & 33.2 & 12 \\
\hline \multirow[t]{2}{*}{ Leucocytes $\left(\times 10^{9} / I\right)$} & $4-11$ & Pre & 7.9 & 2 & $7 \cdot 0$ & 1 & $7 \cdot 8$ & 1 & 7.5 & 1 \\
\hline & & Post & $7 \cdot 2$ & 1 & $6 \cdot 9$ & 1 & $7 \cdot 9$ & 1 & $7 \cdot 6$ & 2 \\
\hline \multirow[t]{2}{*}{$\mathrm{Hb}(\mathrm{g} / \mathrm{dl})$} & $120-170$ & Pre & $150 \cdot 3$ & 11 & $149 \cdot 6$ & 9 & $153 \cdot 6$ & 11 & $146 \cdot 9$ & 12 \\
\hline & & Post & $147 \cdot 2$ & 9 & 149.5 & 10 & $152 \cdot 3$ & 11 & $146 \cdot 1$ & 11 \\
\hline \multirow[t]{2}{*}{ Haematocrit (I/l) } & $0.36-0.51$ & Pre & 0.4 & 0 & 0.4 & 0 & $0.5 \dagger$ & 0 & 0.4 & 0 \\
\hline & & Post & 0.4 & 0 & 0.4 & 0 & 0.4 & 0 & 0.4 & 0 \\
\hline \multirow[t]{2}{*}{ Platelet $\left(\times 10^{9} / l\right)$} & $150-400$ & Pre & $280 \cdot 0 \dagger \dagger$ & 51 & $216 \cdot 8$ & 30 & 248.3 & 51 & 228.8 & 54 \\
\hline & & Post & 261.4 & 45 & 219.8 & 26 & 239.1 & 46 & $220 \cdot 1$ & 46 \\
\hline
\end{tabular}

ALAT, alanine aminotransferase; AST, aspartate aminotransferase; CLA, conjugated linoleic acid.

Mean values were significantly different from those of the placebo group: $\uparrow P=0.03 ; \uparrow \uparrow P=0.01$.

study. In the present study most of the fat mass was lost from the trunk area, which is not surprising since individuals suffering from the metabolic syndrome usually present an accumulation of abdominal fat. The use of the DEXA technique allows not only the study of body composition but also the descriptive study of such modifications in the different areas of the body.

It should be emphasized that this is the first study to be reported in which the mixture of two isomers was assessed in a large number of subjects and also the first in which the effects on body composition were measured using DEXA in both overweight and obese subjects.

It has been claimed that cis-9, trans-11, the main isomer found in the diet, modulates growth ${ }^{29}$, and that trans-10, cis-12 has a beneficial effect on body composition and diabetes in mice ${ }^{30}$. Furthermore, trans-10, cis-12 also has been found to increase insulin resistance in a low percentage of human subjects with metabolic syndrome ${ }^{23}$.

The mechanisms by which CLA may affect body composition are unclear. CLA is believed to accumulate in tissues of animals and man, where it is readily metabolised. In vitro and in vivo studies report that the capacity of CLA to reduce adipose tissue can be explained by one or more of the following mechanisms: the induction of adipocyte apoptosis ${ }^{31}$; reduced accumulation of fatty acids in adipocytes because of an inhibition of lipoprotein lipase and an increase in carnitine palmitoyltransferase in serum ${ }^{32}$; the binding to peroxisome proliferator-activated receptor present in fat tissue and modification of the signalling cascade to down-regulate leptin expression $^{33}$; the prevention of the TAG accumulation in adipocytes $^{34}$; and the modification of the metabolic rate ${ }^{11,35}$.

In the present study, energy intake slightly increased throughout the study in both experimental groups, although differences were not significant. This observation indicates that the effects of CLA on fat mass are diet-independent. Exercise and use of tobacco did not differ significantly between groups, and therefore neither factor can explain the changes in body composition observed in the CLA group.
Although CLA supplementation was associated with a change in body composition, it was not related to significant alterations of metabolic parameters. Previous studies on CLA report contradictory effects on blood lipids, which have recently been reviewed ${ }^{36}$. According to Tricon et al. ${ }^{37}$, trans-10, cis-12-CLA could increase both total and LDLcholesterol concentrations more than the cis-9, trans-11CLA isomer. However, none of the studies reviewed in this report $^{36}$ described significant effects attributable to CLA intake on the concentrations of total cholesterol or LDLcholesterol. Smedman \& Vessby ${ }^{18}$ observed, as we did in the present study, increases in LDL-cholesterol levels in the group receiving CLA, although the changes observed were not significantly different from the control. In principle, nonsignificant changes should be considered as fluctuations within the normal physiological range. Moreover, in the present study they were not reproduced in the other BMI subgroup $(>30)$. As to other possible modifications of the lipid profile, the literature contains references to HDL reduction $^{16,15}$, VLDL reduction ${ }^{38}$ or any effect on cholesterol $^{21}$. In the present study, no significant variation in total cholesterol or TAG variations were observed. In a similar study, Basu et al. ${ }^{39,40}$ showed that men with metabolic syndrome increased $\mathrm{F}_{2}$-isoprostane excretion after supplementation with a CLA isomer mixture. This increased excretion returned to baseline levels 2 weeks after withdrawing CLA treatment. These findings indicate that CLA may induce lipid peroxidation; however, we did not test these possible effects in the present study.

We did not observe changes in fasting plasma glucose, blood pressure or insulin sensitivity estimates. Riserús et al. ${ }^{20}$ showed an increased insulin resistance after 12 weeks of treatment with trans-10, cis-12-CLA isomer, in a male population with metabolic syndrome. Notably this effect was not observed when the mixture of isomers (Tonalin ${ }^{\circledR}$ mixture used in the present study) was used ${ }^{20}$.

We detected a significant reduction of alanine aminotransferase in the overall CLA group but the statistical significance 
Table 4. Review comparing published results

\begin{tabular}{|c|c|c|c|c|c|c|}
\hline Authors and year & Journal and reference number & $\begin{array}{c}\text { No. of cases/control } \\
\text { and sex }\end{array}$ & Isomers, dosage and duration & Method & $\begin{array}{l}\text { BMI averages, } \\
\text { cases/control }\end{array}$ & Results, BFM \% \\
\hline Thom et al. (2000) & $J$ Int Med Res ${ }^{19}$ & $\begin{array}{l}10 / 10 \\
\text { Men }\end{array}$ & $\begin{array}{l}\text { CLA } c 9, t 11 ; \text { CLA } t 10, c 12 ; \text { CLA } \\
\quad c 11, t 13 ; \text { CLA } t 8, c 10 \\
1.8 \mathrm{~g} \\
3 \text { months }\end{array}$ & Near IR light & $<25$ & Reduction BFM \\
\hline Riserús et al. (2001) & $\begin{array}{l}\text { Int J Obes Relat Metab } \\
\text { Disord }\end{array}$ & $\begin{array}{l}14 / 10 \\
\text { Men } \\
\text { Metabolic standard }\end{array}$ & $\begin{array}{l}\text { CLA t10,c12; CLA } c 9, t 11 \\
4 \mathrm{~g} \\
4 \text { weeks }\end{array}$ & SAD (anthropometry) & $32 \cdot 1 / 31 \cdot 7$ & Reduction SAD $(0.6 \mathrm{~cm})$ \\
\hline Blankson et al. (2000) & J Nutr ${ }^{17}$ & $\begin{array}{l}7 / 8 \\
\text { Men and women }\end{array}$ & $\begin{array}{l}\text { CLA t10,c12; CLA } c 9, t 11 \\
3.4 \mathrm{~g} \\
3 \text { months }\end{array}$ & DEXA & $27 \cdot 7 / 28 \cdot 2$ & Reduction, $6 \%$ \\
\hline Riserús et al. (2002) & Diabetes Care ${ }^{20}$ & $\begin{array}{l}19 / 19 \\
\text { Men } \\
\text { Metabolic standard }\end{array}$ & $\begin{array}{l}1 \text { group CLA t10,c12; } \\
1 \text { group CLA t10,c12; CLA } c 9, t 11 \\
3.4 \mathrm{~g} \\
3 \text { months }\end{array}$ & SAD impedance & $30 \cdot 1 / 30 \cdot 2$ & No reduction \\
\hline $\begin{array}{l}\text { Smedman \& Vessby } \\
\quad(2001)\end{array}$ & Lipids $^{18}$ & $\begin{array}{l}\text { 25/25 } \\
\text { Men and women }\end{array}$ & $\begin{array}{l}\text { CLA t10,c12; CLA } c 9, t 11 \\
4.2 \mathrm{~g} \\
3 \text { months }\end{array}$ & Impedance & $20-25$ & Reduction, $3.8 \%$ \\
\hline Kamphuis et al. (2003) & $\begin{array}{l}\text { Int J Obes Relat Metab } \\
\text { Disord }\end{array}$ & $\begin{array}{l}30 / 30 \\
\text { Men and women }\end{array}$ & $\begin{array}{l}\text { CLA t10,c12; CLA } c 9, t 11 \\
3.6 \mathrm{~g} \\
3 \text { months }\end{array}$ & Hydrodensitometry & $26 \cdot 2 / 25 \cdot 7$ & No reduction \\
\hline $\begin{array}{l}\text { Gaullier et al. } \\
\quad(2004,2005)\end{array}$ & $\begin{array}{l}A m J \operatorname{Clin} \mathrm{Nutr}^{27} \text { and } \\
\mathrm{Nutr^{28 }}\end{array}$ & $\begin{array}{l}60 / 59 \\
\text { Men and women }\end{array}$ & $\begin{array}{l}\text { CLA t10,c12; CLA c9,t11 } \\
4.5 \mathrm{~g} \\
12 \text { months, follow-up } 24 \text { months }\end{array}$ & DEXA & $28 \cdot 2 / 27 \cdot 7$ & $\begin{array}{l}\text { Reduction, } 7.5 \% \text { (from 6th } \\
\text { to } 12 \text { th month) }\end{array}$ \\
\hline $\begin{array}{l}\text { Malpuech-Brugere } \\
\text { et al. (2004) }\end{array}$ & Obes $\operatorname{Res}^{25}$ & $\begin{array}{l}45 / 45 \\
\text { Men and women }\end{array}$ & $\begin{array}{l}1 \text { group CLA } t 10, c 12 \\
1 \text { group CLA } c 9, t 11 \\
1.5 \text { and } 3 \mathrm{~g} \\
4 \text { months }\end{array}$ & DEXA & $27 \cdot 7 / 27 \cdot 7$ & No reduction \\
\hline
\end{tabular}




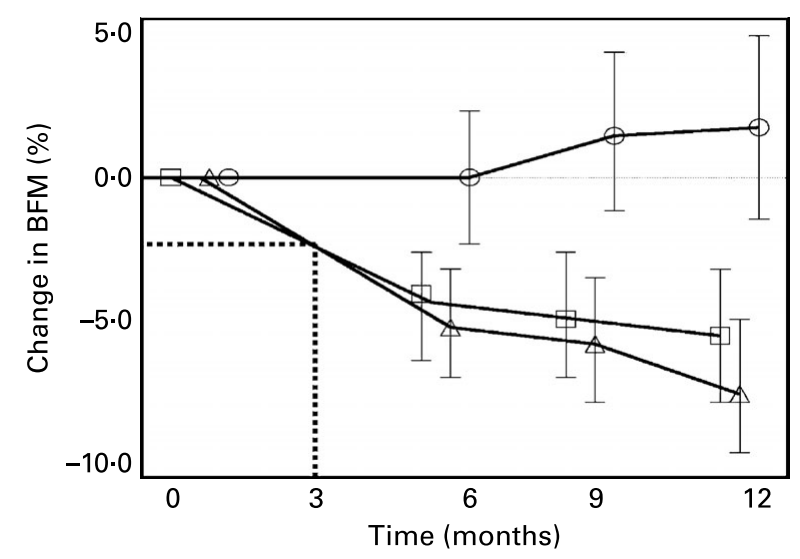

Fig. 3. Fig. taken from Gaullier et al. ${ }^{27}$ and modified for the present study (….). BFM, body fat mass.

disappeared when the groups were stratified by BMI. Alanine aminotransferase can be considered a marker for fat liver degeneration, which can occur in obese subjects. Studies such as that by Tsuboyama-Kasaoka et $a l .{ }^{41}$ show that high doses of CLA induce liver enlargement and lipodystrophy in experimental animals. The dose of CLA like the ones used in the present study does not affect hepatic function, or may even favour the normalisation of certain enzymes.

We performed a 'per protocol' analysis on compliant patients with no major protocol violations, in order to quantify the effect of the intervention with a limited sample size. Patients were randomised when they entered the study, and so any slight variations between the subgroup studied at baseline are attributable to chance alone. For example, the CLA group with the lowest weight (BMI < 30) showed greater total fat mass in the DEXA compared with placebo group.

The degree of compliance was high in the present study, over $99 \%$. This high compliance rate demonstrates good tolerance of CLA milk (Naturlinea with Tonalin ${ }^{\circledR}$ ). Only $3.5 \%$ of the CLA group and $26.6 \%$ of the control group showed slight adverse effects in gastrointestinal symptoms such as abdominal discomfort, laxative effects and flatulence. These adverse effects have been described by other authors ${ }^{17-20}$. Moreover, the lack of alterations in haematological parameters and renal function further supports the security of milk supplemented with CLA.

In conclusion, $3 \mathrm{~g}$ CLA supplementation (Naturlinea with Tonalin $\left.{ }^{\circledR}\right)$, over a 12 -week period produced a significant reduction of fat mass in overweight subjects with a BMI $\leq 30$. CLA supplementation was not associated with any adverse effects or biological changes. Further long-term studies are needed to evaluate more important reductions or to assess the effects in obese subjects. The present data indicate that CLA supplementation may be a useful approach to reduce fat mass, which is a prominent cardiovascular risk factor.

\section{Acknowledgements}

This study was supported by the Corporación Alimentaria Peñasanta, The Spanish Ministry of Health, Institute Carlos III (Ciber CB06/03, Fisiopatologia, obesidad y Nutrición) and DURSI GRC2005SGR00039. We especially wish to thank Roser Mestres, Blanca Valero, Isidora Torralba and Eva Suárez (Rosselló Primary Care Centre), María Mongay, Mònica Domenech and Cristina Sierra (Hypertension Unit, Hospital Clinic, Barcelona), and Ana Pérez, Berenice Cortés and Mercè Serra (Lipids Unit, Hospital Clinic, Barcelona) for facilitating the recruitment of patients.

\section{References}

1. Pariza MW, Park Y \& Cook ME (1999) Conjugated linoleic acid and the control of cancer and obesity. Toxicol Sci 52, 107-110.

2. Pariza M, Ashoor S, Chu F \& Lund D (1979) Effects of temperature and time on mutagen formation in pan-fried hamburger. Cancer Lett 7, 63-69.

3. Zu HX \& Schut HA (1992) Inhibition of 2-amino-3-methylimidazol (4,5-f) quinoline-DNA adduct formation in CDF1 mice by heat-altered derivatives of linoleic acid. Food Chem Toxicol 30, 9-16.

4. Ip C, Singh M, Thompson HJ \& Scimeca JA (1994) Conjugated linoleic acid suppresses mammary carcinogenesis and proliferative activity of the mammary gland in the rat. Cancer Res 54, $1212-1215$.

5. Liew C, Schut HA, Chin SF, Pariza MW \& Dashwood RH (1995) Protection of conjugated linoleic acids against 2-amino-3-methylimidazol (4,5-f) quinoline-induced colon carcinogenesis in the F344 rat: a study of inhibitory mechanisms. Carcinogenesis 16, 3037-3043.

6. Schonberg S \& Krohan HE (1995) The inhibitory effect of conjugated dienoic derivatives (CLA) of linoleic acid on the growth of human tumor cell lines is in part due to increased lipid peroxidation. Anticancer Res 15, 1241-1246.

7. Cunningham DC, Harrison LY \& Shultz TD (1997) Proliferative responses of normal human mammary and MCF-7 breast cancer cells to linoleic acid, conjugated linoleic acid and eicosanoid synthesis inhibitors in culture. Anticancer Res 17, 197-203.

8. Wong MW, Chef BP, Wong TS, Hosick HL, Boylston TD \& Schultz TD (1997) Effects of dietary conjugated linoleic acid on lymphocyte function and growth of mammary tumors in mice. Anticancer Res 17, 987-993.

9. Lee KN, Kritchevsky D \& Pariza MW (1994) Conjugated linoleic acid and atherosclerosis in rabbits. Atherosclerosis $\mathbf{1 0 8}$, $19-25$.

10. Miller C, Park Y, Pariza MW \& Cook M (1994) Feeding conjugated linoleic acid to animals partially overcomes catabolic responses due to endotoxin injection. Biochem Biophys Res Commun 198, 1107-1112.

11. West DB, Delany JP, Camet PM, Blohm F, Truett AA \& Scimeca J (1998) Effects of conjugated linoleic acid on body fat and energy metabolism in mouse. Am J Physiol 275, R667-R672.

12. Park Y, Allbright KJ, Liu W, Storkson JM, Cooj ME \& Pariza MW (1997) Effects of conjugated linoleic acid on body composition in mice. Lipids 32, 853-858.

13. German JB, Dilard CJ \& Ward RE (2002) Bioactive components in milk. Curr Opin Clin Nutr Metab Care 5, 653-658.

14. Yu L, Adams D \& Watkins BA (2003) Comparison of commercial supplements containing conjugated linoleic acids. J Food Composit Anal 16, 419-428.

15. Nagao K \& Yanagita T (2005) Conjugated fatty acids in food and their health benefits. J Biosci Bioeng 100, 152-157.

16. Gaullier JM, Berven $\mathrm{G}$, Blankson $\mathrm{H}$ \& Gudmundsen $\mathrm{O}$ (2002) Clinical trial results support a preference for using 
CLA preparations enriched with two isomers rather than four isomers in human studies. Lipids 37, 1019-1025.

17. Blankson H, Stakkestad JA, Fagertum H, Thom E, Wadstein J \& Gudmunsen O (2000) Conjugated linoleic acid reduces body fat mass in overweight and obese humans. J Nutr 130, 2943-2948.

18. Smedman A \& Vessby B (2001) Conjugated linoleic acid supplementation in humans - metabolic effects. Lipids 36, 773-781.

19. Thom E, Wadstein J \& Gudmunsen O (2001) Conjugated linoleic acid reduces body fat in healthy exercising humans. $J$ Int Med Res 29, 392-396.

20. Riserús U, Arner P, Brismar K \& Vessby B (2002) Treatment with dietary trans-10 cis-12 conjugated linoleic acid causes isomer-specific insulin resistance in obese men with metabolic syndrome. Diabetes Care 25, 1516-1521.

21. Berven G, Bye A, Hals O \& Karlsen OA (2000) Safety of conjugated linoleic acid (CLA) in overweight or obese human volunteers. Eur J Lipid Sci Technol 102, 455-462.

22. Zambell KL, Keim NL, Van Loan MD, Gale B, Benito P, Kelley DS \& Nelson GJ (2000) Conjugated linoleic acid supplementation in humans: effects on body composition and energy expenditure. Lipids 35, 777-782.

23. Riserús U, Berglund L \& Vessby B (2001) Conjugated linoleic acid (CLA) reduced abdominal adipose tissue in obese middleaged men with signs of metabolic syndrome: a randomised controlled trial. Int J Obes Relat Metab Disord 25, 1129-1135.

24. Kamphuis MM, Lejeune MP, Saris WH \& Westerterp-Plantenga MS (2003) The effect of conjugated linoleic acid supplementation after weight loss on body weight regain, body composition, and resting metabolic rate in overweight subjects. Int $J$ Obes Relat Metab Disord 27, 840-847.

25. Malpuech-Brugere C, Verboeket-van de Venne WP, Mensink RP, Arnal MA, Morio B, Brandolini M, Saebo A, Lassel TS, Chardigny JM, Sebedio JL \& Beaufrere B (2004) Effects of two conjugated linoleic acid isomers on body fat mass in overweight humans. Obes Res 12, 591-598.

26. Craig CL, Marshall Al, Sjostrom M, Bauman AE, Booth ML, Ainsworth BE, Pratt M, Ekelund U, Yngve A, Sallis JF \& Oja $P$ (2003) International Physical Activity Questionnaire (IPAQ): 12-country reliability and validity. Med Sci Sports Exer 35, 1381-1395.

27. Gaullier JM, Halse J, Hoye K, Kristiansen K, Fagertun H, Vik H \& Gudmundsen O (2004) Conjugated linoleic acid supplementation for 1 year reduces body fat mass in healthy overweight humans. Am J Clin Nutr 79, 1118-1125.

28. Gaullier JM, Halse J, Hoye K, Kristiansen K, Fagertun H, Vik H \& Gudmundsen O (2005) Supplementation with conjugated linoleic acid for 24 months is well tolerated by and reduces body fat mass in healthy, overweight humans. J Nutr 135, 778-784.
29. Pariza MW, Park Y \& Cook ME (2001) The biologically active isomers of conjugated linoleic acid. Prog Lipid Res 40, 283-298.

30. Park Y, Storckson JM, Albright KJ, Liu W \& Pariza MW (1999) Evidence that the trans-10,cis-12 isomers of conjugated linoleic acid induces body composition changes in mice. Lipids 34, 235-241.

31. Evans M, Geigerman C, Cook J, Curtis L, Kuebler B \& McIntosh M (2000) Conjugated acid linoleic suppresses triglyceride accumulation and induces apoptosis in 3T3-L1 preadipocytes. Lipids 35, 899-910.

32. Park Y \& Pariza MW (2001) The effects of dietary conjugated nonadecadienoic acid and body composition in mice. Biochim Biophys Acta 1533, 171-174.

33. Kallen C \& Lazar M (1996) Antidiabetic thiazolidinediones inhibit leptin on gene expression in 3T3-L1 adipocytes. Proc Natl Acad Sci USA 93, 5793-5796.

34. Granlud L, Juvet L, Pedersen J \& Nebb H (2003) Trans 10, cis 12-conjugated linoleic acid prevents triacylglycerol accumulation in adipocytes by acting as a PPARgamma modulator. J Lipid Res 44, 1441-1452.

35. Szymczyk B, Pisulewski PM, Szczurek W \& Hanczakowski P (2001) Effects of conjugated linoleic acid on growth performance, feed conversion efficiency, and subsequent carcass quality in broiler chickens. Br J Nutr 85, 465-473.

36. Salas-Salvado J, Marquez-Sandoval F \& Bullo M (2006) Conjugated linoleic acid intake in humans: a systematic review focusing on its effect on body composition, glucose, and lipid metabolism. Crit Rev Food Sci Nutr 46, 479-488.

37. Tricon S, Burdge G, Kew S, et al. (2004) Opposing effects of cis-9,trans-11 and trans-10,cis-12 conjugated linoleic acid on blood lipids in healthy humans. Am J Clin Nutr 80, 614-620.

38. Noone EJ, Roche HM, Nugent AP \& Gibney MJ (2002) The effect of dietary supplementation using isomeric blends of conjugated linoleic acid on lipid metabolism in healthy human subjects. Br J Nutr 88, 243-251.

39. Basu S, Riserús U, Turpeinen A \& Vessby B (2000) Conjugated linoleic acid induces lipid peroxidation in men with abdominal obesity. Clin Sci 99, 511-516.

40. Basu S, Smedman A \& Vessby B (2000) Conjugated linoleic acid induces lipid peroxidation in humans. FEBS Lett $\mathbf{4 6 8}$, $33-36$.

41. Tsuboyama-Kasaoka N, Takahashi M, Tanemura K, Kim HJ, Tange T, Okuyama H, Kasai M, Ikemoto S \& Ezaki O (2000) Conjugated linoleic acid supplementation reduces adipose tissue by apoptosis and develops lipodystrophy in mice. Diabetes 49, 1534-1542. 